\title{
Multi-temporal monitoring of cotton growth through the vegetation profile classification for Tashkent province, Uzbekistan
}

\author{
Jasmina Gerts ${ }^{1}-$ Mukhiddin Juliev $^{1 凶}-$ Alim Pulatov $^{1}$ \\ ${ }^{1}$ Tashkent Institute of Irrigation and Agricultural Mechanization Engineers, TIIAME, Tashkent, Uzbekistan

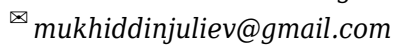

\begin{abstract}
As satellite data of the Earth surface seems to be of vital importance for many applications, classification of land use and land cover has been found to vary dramatically in different approaches. In this paper, modified classification algorithm of remote sensing data is presented for processing medium and high spatial resolution satellite images like Landsat and Sentinel in Tashkent province of Uzbekistan. The results of NDVI (Normalized difference vegetation index) profile analysis via Spectral Correlation Mapper classification are shown for the period 1994-2017. It is implied, that combination of optical and radar data with application of Spectral Correlation Mapper classification improve the results of classification for a specific dataset by considering such factors as overall classification accuracy and time and labor involved.
\end{abstract}

\section{Highlights for public administration, management and planning:}

- The Spectral correlation classification method of NDVI profiles is presented resulting in higher accuracy of cotton growth-related land use estimations.

- A change in agricultural land use of Uzbekistan since the 1990s was detected, in spite of the decreasing trend of cotton plantations after 2004.

- The presented approach may assist to reveal the effects of agricultural policies and environmental change on land use.

\section{Keywords}

Agriculture

Land use classification,

Remote sensing,

NDVI profile,

Spectral correlation

mapper,

Uzbekistan

Received:

23 January 2019

Received in revised form: 29 May 2020

Accepted:

4 June 2020

\section{Introduction}

History of the cotton production is quite long in Uzbekistan and its production and export is one of the leading branches of agriculture. If in Central Asia 2 million tons of cotton fiber are grown per year, 1.4 million of them are Uzbek fiber. Another name of cotton in Uzbekistan is "white gold". Nowadays, cotton-wheat-rice or cotton-wheat crop rotations are the main crop system in Uzbekistan (Djanibekov et al. 2010). During the years of sovereign development in the republic, the task was set - to achieve grain independence. The structure of the acreage was changed, the farms gained autonomy and could themselves decide which crop to sow. In such conditions true understanding of the LULC spatiotemporal change process in Uzbekistan since 1991 is in importance (Kahriz et al. 2019).
Remote Sensing images in recent years became an indispensable tool in a variety of surface land use studies. According to some authors (Seto et al. 2002), land use and land cover are often used interchangeably, but the two concepts are not exactly the same. The latter measures the physical attributes or characteristics of the Earth's surface, while the former describes how land cover is utilized. Remote Sensing (RS) detects land cover, not land use, though in most cases one can derive land use from land cover. RS changedetection studies use the two concepts interchangeably (e.g. Heikkonen \& Varfis 1998; Muttitanon \& Tripathi 2005) because land use often corresponds to land cover. For instance, in cultivated environments, cropland could describe land use type, while at the same time it is a form of land cover. In such scenarios, the two concepts could be considered as synonymous (Kiage et al. 2006). In this article the term land use will be used. 


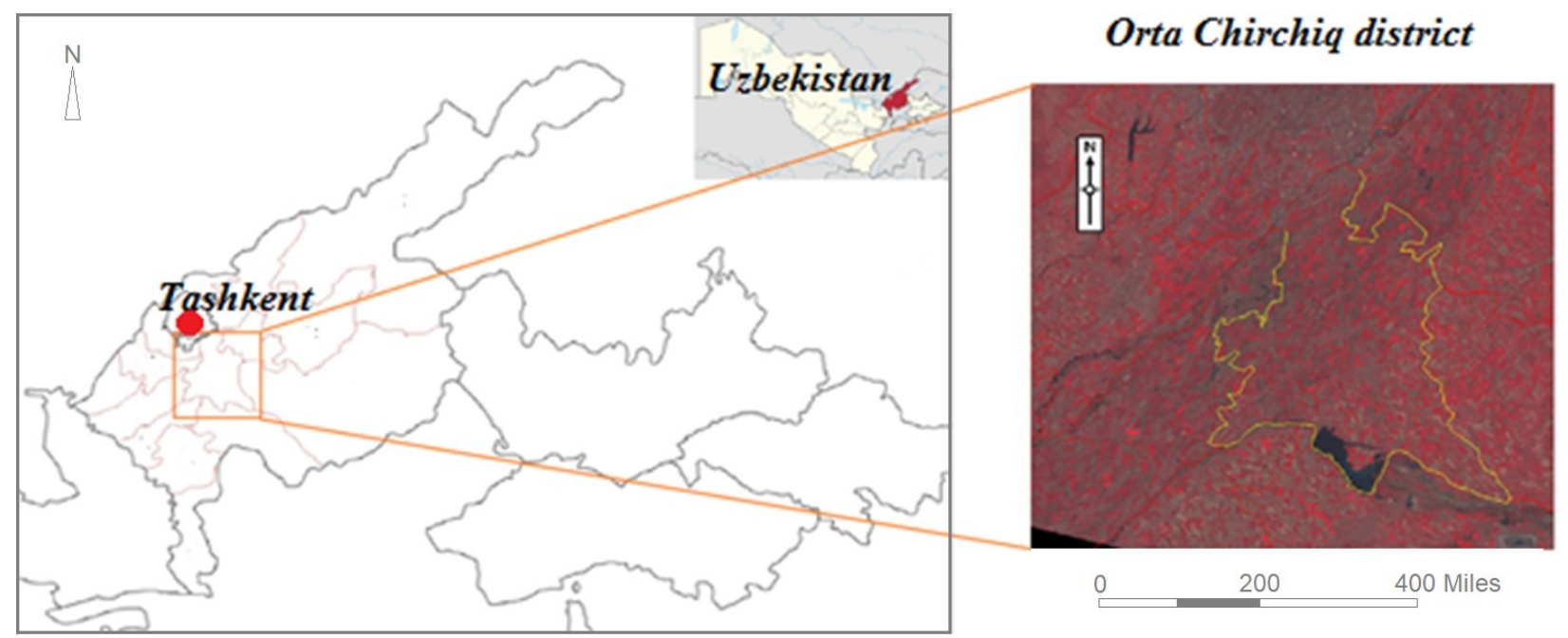

Fig. 1 Study area

Satellite-based RS offers an accurate, time and costefficient tool for monitoring and mapping crop allocation at different scales (e.g., Conrad et al. 2011; GEOSS 2009). Essentially, last research on agricultural land use shows that over the last decade interest of using RS satellite imageries are increased widely rather than field data measurement on the ground in Central Asia (Hamidov et al. 2016). At the same time, the need to obtain reliable data on the surface is constantly increasing as a consequence of constantly observed changes in the landscape.

The requirement to obtain reliable results in solving the problem of classification determines the need for processing procedures with probabilistic characteristics. Modern remote sensing systems have a different number of spectral channels, making it difficult to conduct a visual image classification, so the classification algorithms are implemented in various software designed to work with remote sensing data.

Each of them provide different level of overall accuracy of land cover classification. For instance, some determine $87 \%$ accuracy and $98 \%$ when classified only into two classes like water/soil (Edlinger et al. 2012), other set $96.17 \%$ after merging with highresolution images and with the standard type only 75.88\% (Yeshaneh et al. 2013), researchers in China showed $80.89 \%$ accuracy with the additional use of four different indices (Tian et al. 2014). At the same time Platonov et al. (2008) and Zhang et al. (2011) show NDVI threshold value for several crop types in agriculture and emphasized on importance of phenological crop development knowledge on detecting spectral signatures of certain crops in Central Asia. Conrad et al. (2011) analysed land use classification assessment with using NDVI methods by utilizing MODIS satellites with low spatial resolution $250 \mathrm{~m}$, in Khorezm province of the Uzbekistan. In this way we found a lack of information in regard to the best algorithms for land use classification analysis, especially for cotton growth.

The major objectives of this research are to evaluate the effectiveness of Spectral correlation mapper classification method in combination with NDVI optical and radar data for monitoring of cotton growth in Uzbekistan in 1994-2017.

\section{Materials and methods}

\subsection{Study area}

This study was conducted in Orta Chirchiq district of Tashkent Region in Uzbekistan, which was established in 1926. The capital of the district is Toytepa town. The population of the district is about 163 400 people and the total area is $510 \mathrm{~km}^{2}$ (Fig. $1)$. The corresponding time zone is UTC+5 (UZT). On considerable part of the district, the vegetation period of plants exceeds 200 days. Favorable climatic terms allow tilling a cotton plant and other heat-loving cultures, get 2-3 harvests of vegetables in a year (Glazirin et al. 1999).

\subsection{Data}

The data used in the study include Landsat and Sentinel raster images that were obtained in the open Internet resources of the United States Geological Survey (USGS) Center for Earth Resources Observation and Science (EROS) and Sentinel 
Table 1 Sensors characteristics

\begin{tabular}{llllll}
\hline & Landsat TM5 & Landsat 7ETM+ & Landsat 8OLI & Sentinel 2 & Sentinel 1A \\
\hline Launched & March 1984 & April 1999 & February 2013 & June 2015 & April 2014 \\
Source & NASA & NASA & NASA & ESA & ESA \\
Swath wide & $185 \mathrm{~km}$ & $185 \mathrm{~km}$ & $185 \mathrm{~km}$ & $290 \mathrm{~km}$ & $250 \mathrm{~km}$ \\
Orbit & $705 \mathrm{~km}$ & $705 \mathrm{~km}$ & $705 \mathrm{~km}$ & $786 \mathrm{~km}$ & $786 \mathrm{~km}$ \\
Temporal resolution & 16 days & 16 days & $16 \mathrm{days}$ & $2-5$ days & $2-6 \mathrm{days}$ \\
Spatial resolution & $30 / 120 \mathrm{~m}$ & $15 / 30 / 60 \mathrm{~m}$ & $15 / 30 / 100 \mathrm{~m}$ & $10 / 20 / 60 \mathrm{~m}$ & $5 \times 20 \mathrm{~m}$ \\
Spectral resolution (bands) & 7 & (PAN/VIS/TIR) & (PAN/VIS/TIR) & 13 & 4 \\
\hline
\end{tabular}

ESA sources. It is important to note, that Landsat is an operational imaging system and each scene is ordered in a so-called World Reference System (WRS), where Orta-Chirchiq district is located at path 154 and row 31. The spatial resolution of Landsat images varies from $15 \mathrm{~m}$ in panchromatic band, to $30 \mathrm{~m}$ in the rest bands not taking into account thermal layers. Approximate scene size is $170 \mathrm{~km}$ north-south by $183 \mathrm{~km}$ east-west. More descriptive information about used satellites are shown in (Table 1).

The total temporal range of acquired data corresponds to April - November due to the phenological conditions and higher NDVI values in this period of the year (Table 2). Other useful data included the co-registered vector administrative boundary of Orta-Chirchiq district, which was generated by ESRI ArcGIS 10.2 software based on scanned topography map, and later was used as masks to get subset-images of the study area. At the same time for the classification model expert information on the phenological crop development in the region was very important. This information is expected to determine mainly the spatial and temporal land use distribution in the study area. Field data were collected between June and August in 2017 and 105 ground control points were collected for the further use in accuracy assessment. Google Earth and Google map data as well as local authorities wheat map for 2017 were used as a supplementary source of information.

\subsection{Conceptual framework}

The experiment was performed combining Spectral Correlation Mapper classification of NDVI profile to Sentinel radar and optical images. The flow chart of the proposed methodology is presented in Fig. 2, comprising the following major steps: data collection, preprocessing, NDVI calculation, SCM classification, merging to Sentinel images, results analysis (Fig. 2).

Table 2 Landsat (LT5 - Thematic Mapper , LT7 - ETM+ and LC8 - Landsat OLI) images, used for the classification

\begin{tabular}{|c|c|c|c|c|c|}
\hline & 1994 & 1999 & 2009 & 2014 & 2017 \\
\hline \multirow[t]{2}{*}{ April } & & LT5 April 13 & LT5 April 8 & LC8 April 6 & LC8 April 14 \\
\hline & & & LT5 April 24 & LC8 April 22 & LC8 April 30 \\
\hline \multirow[t]{2}{*}{ May } & LT5 May 1 & & LT5 May 26 & LC8 May 24 & LC8 May 16 \\
\hline & LT5 May 17 & & & & \\
\hline \multirow{2}{*}{ June } & LT5 June 2 & & LT5 June 11 & LC8 June 25 & LC8 June 1 \\
\hline & & & LT5 June 27 & & \\
\hline \multirow[t]{2}{*}{ July } & LT5 July 4 & LT7 July 10 & LT5 July 29 & LC8 July 27 & LC8 July 3 \\
\hline & LT5 July 20 & & & & LC8 July 19 \\
\hline \multirow[t]{2}{*}{ August } & LT5 August 21 & LT5 August 19 & & LC8 August 12 & LC8 August 12 \\
\hline & & LT7 August 27 & & LC8 August 28 & \\
\hline \multirow[t]{2}{*}{ September } & LT5 September 6 & & & LC8 September 29 & LC8 September 16 \\
\hline & & & & & LC8 September 21 \\
\hline October & LT5 October 8 & & LT5 October 17 & & \\
\hline November & & & LT5 November 18 & & \\
\hline
\end{tabular}




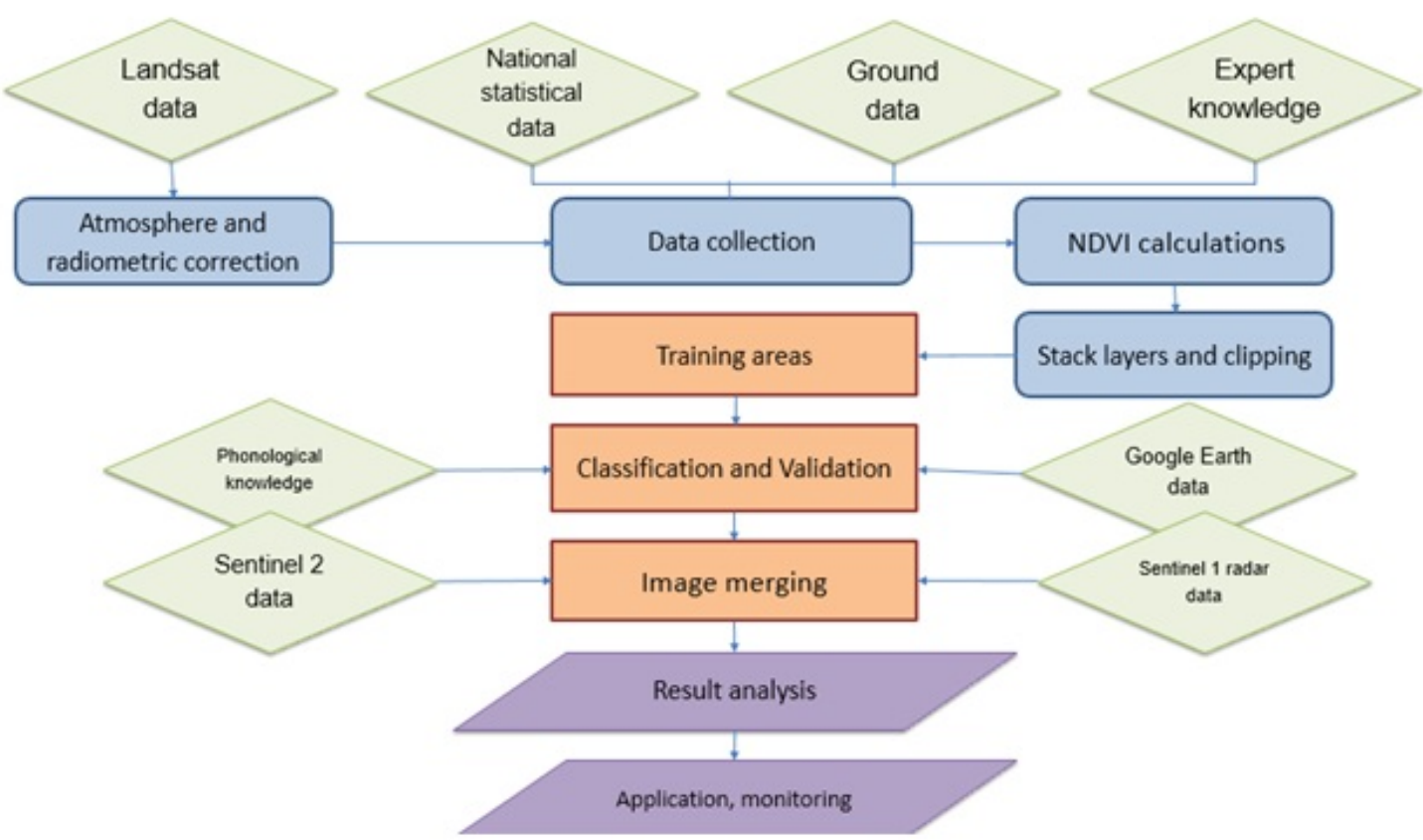

Fig. 2 Flowchart of the research

The following land use/cover classes were used for interpreting the satellite images: cotton, rice, wheat, gardens including other crop types and small parts of the high-vegetated areas, and settlements including residential area.

\subsection{Data processing}

Six temporal datasets (1994, 1999, 2004, 2009, 2014,2017 ) were chosen to identify changes in land use of Tashkent province. However due to the problems on Scan Line Corrector at Landsat 7 ETM+ data during 2004 were not appropriate to use in the procedure, so only five years were taken for the further analysis.

Thirty-seven Landsat images (Table 2) were preprocessed by ATCOR module in ERDAS software to reduce atmospheric haze (light fog), atmospheric and topographic correction. Data had been enhanced in the pre-processing stage by different filters like high pass and medium filter in order of attenuation the effects of noise and improve the data quality spectrally and spatially (Lillesand et al. 2015).

NDVI images were created with the use of NIR and RED layers of Landsat and Sentinel2 satellites. Received NDVI images from multiple time steps within one vegetation period were stacked and displayed. The NDVI profiles of the visually separable classes were compared with phenological stages of the typical crops from the study area. Five typ- ical spectral curves were detected in the received image: one peaked in May, but showed low values afterwards (yellow); another with peak in August acquisitions (brown); one with higher peak in $\mathrm{Au}$ gust and relatively very low NDVI in May (blue); one with increasing values in spring but with stable decreasing curve in the rest period (green) and the last with NDVIs increasing only to soil line level 0.3 and not higher (red). On the basis of expert knowledge and presented classes in the study area these colors were corresponded as follows: yellow - wheat, brown - cotton, blue - rice, green - gardens and red - residential area (Fig. 3). The bands on the graph correspond to the NDVI layers in 2017 as follows: 1 - April 14, 2- April 30, 3 - May 16, 4 - June 1, 5 - July 3, 6 - July 19, 7 - August 12, 8 September 16, 9 - September 21.

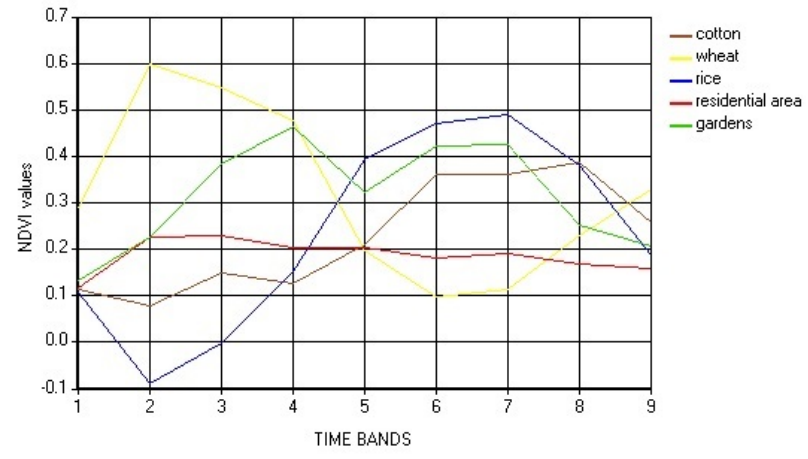

Fig. 3 NDVI profile for April - September 2017 
The Spectral correlation mapper (SCM) classification was conducted and assessed the recognition of figures with negative relationship and produces better outcomes for elimination of shading impact (De Carvalho \& Meneses 2000). These classification methods for feature spectra is based on a comparison of the spectral image with a reference spectrum (endmembers or spectral libraries).

The well separated training polygons were digitized on-screen dependent on territory information obtained during field work. The pixels in the polygons that were chosen as illustrative of each class were plotted in spectral space and a visual check was made that all classes could be isolated in no less than one band combination.

As the spatial resolution of used Landsat layers is 30 by 30 meters, boundaries between the fields suffered the problem of classification and so merging of NDVI profile for 2017 was applied to Sentinel 2 image of August 8. Landsat NDVI layers were resampled to the higher resolution and 10 layers in total for 2017 and were analyzed later on (Fig.4).

At the final step, radar Sentinel 1 image from June was used in order to calculate radar NDVI by comparison VV and VH polarizations. The result of subtraction of these polarizations was analyzed for further visual interpretation and comparison.For accuracy assessment 105 random sampling points in Water users Association "Sof oq oltin" of Orta Chirchiq district were collected. The number of the points were evaluated in accordance to the formula, introduced by Cochran (1997).

$$
n=\left(\frac{\sum_{i=1} w_{i} s_{i}}{S(O)}\right)^{2}
$$

where $\mathrm{n}$ - number of the pixels in the area; $\mathrm{S}(\mathrm{O})$ - standard error; Wi - part of i-class from the total area; $\mathrm{Si}$ - standard deviation of i-class calculated as

$$
S_{i}=\sqrt{U_{i}\left(1-U_{i}\right)}
$$

As n usually too large in comparison to the rest parts of the formula, the second term is not taken into account. During the sample determination, the values of some indicators from formula 1 are set based on the previous experience of the researcher. From these considerations, for each category, the user error values (Ui) specified in the Table 3 are selected. The standard error of the total accuracy indicator is also independently selected (in this case, the reliability level was set as 95\% (S (O) = 0.05).
Table 3 Values for control points number evaluation

\begin{tabular}{lrrrr}
\hline & $\mathrm{N}$ & $\mathrm{W}$ & $\mathrm{U}$ & $\sqrt{U(1-U)}$ \\
\hline wheat & 10083 & 0.3707 & 0.95 & 0.22 \\
cotton & 10007 & 0.3679 & 0.85 & 0.36 \\
rice & 925 & 0.0340 & 0.75 & 0.43 \\
gardens & 1041 & 0.0383 & 0.65 & 0.48 \\
residential area & 5145 & 0.1891 & 0.99 & 0.10 \\
Total & 27201 & 1.0000 & & \\
\hline
\end{tabular}

\section{Results and discussion}

Classified thematic maps were produced, accuracy was tested and the post classification process was carried out. Spatial patterns of agricultural classes showed various land use clusters and at the same time, it was found that cotton, wheat and rice fields were scattered throughout the region.

Analysis of radar Sentinel1 data allow to conclude that VH polarization in combination with others can be used better to model NDVI in the early stages of vegetation. Compared to VV, VH polarization is more suitable for classifying crops, reducing noise. The double polarization VV - VH allows you to get more accurate results than the double polarization $\mathrm{HH}-\mathrm{HV}$.

By applying the SCM supervised classification of NDVI profiles and improvement of the result by combination and comparisons to Sentinel optical and radar data it was investigated that overall classification accuracy improved for 2017 from 89 to $93 \%$ with a kappa coefficient varying from 0.89 to 0.95 . The kappa coefficient represents the level of agreement between the training samples and land use/cover values in the classified image. The maximum value for kappa occurs when the observed level of agreement is 1. A kappa coefficient greater than 0.80 represents very good level of agreement.

Table 4 summarizes the producer's and user's accuracies for each of five classes before and after Sentinel data. The user's accuracy was calculated by dividing the number of all correctly classified pixels of a class by the sum of all pixels which had been assigned to that class and producer's accuracy was calculated by dividing the number of all correctly classified training pixels of a class by the sum of training data pixels for that class; it indicates the probability of a training pixel being correctly classified (Congalton 1991). The producer's and user's accuracies for 2017 were estimated greater than $81 \%$. 


\section{sciendo}
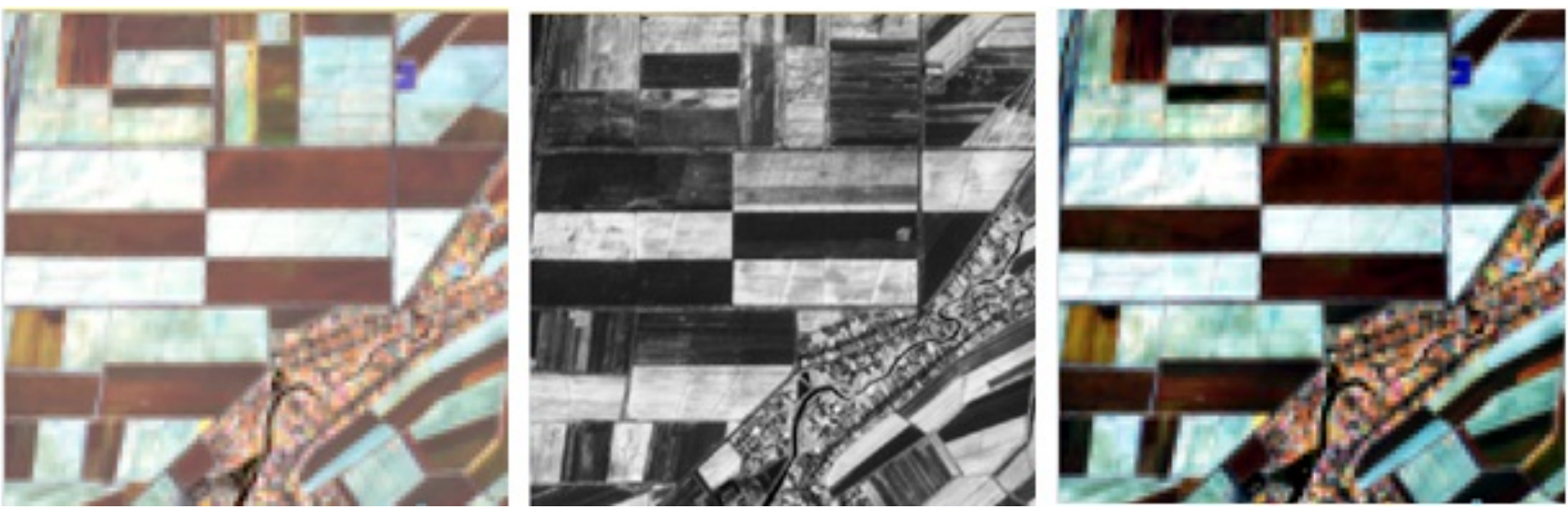

Fig. 4 Image merging (from left to right a) Landsat NDVI image, b) Sentinel 2 image, c) merged image.

Table 4 Mean producer's and user's accuracies in 2017

\begin{tabular}{|c|c|c|c|c|c|c|}
\hline & & $\begin{array}{l}\text { : } \\
\stackrel{0}{ \pm} \\
0\end{array}$ & $\begin{array}{l}\vec{\pi} \\
\stackrel{\mathbb{d}}{\mathbf{d}} \\
\sum_{3}^{4}\end{array}$ & 氙 & 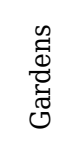 & 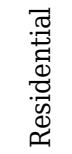 \\
\hline \multirow{2}{*}{$\begin{array}{l}\text { Producer's } \\
\text { accuracy }\end{array}$} & before & $86 \%$ & $95 \%$ & $90 \%$ & $85 \%$ & $86 \%$ \\
\hline & after & $91 \%$ & $95 \%$ & $100 \%$ & $86 \%$ & $91 \%$ \\
\hline \multirow{2}{*}{$\begin{array}{l}\text { User's } \\
\text { accuracy }\end{array}$} & before & $90 \%$ & $95 \%$ & $86 \%$ & $81 \%$ & $90 \%$ \\
\hline & after & $95 \%$ & $95 \%$ & $90 \%$ & $86 \%$ & $91 \%$ \\
\hline
\end{tabular}

At least one acquisition of each month was necessary for a reliable overall accuracy and so the lowest result for 1999 (73\% overall accuracy) could be caused by the absence of images for the period May-June.

The results of the classification show in general a fair congruence with the governmental district level area statistics from 1994. Because of lack in statistical data, comparison of cotton fields was evaluated only for 1994-2014. By implementation of Sentinel data analysis user's accuracy for cotton improved from 90 to $95 \%$ while producer's accuracy from 86 to $91 \%$ respectively. The results obtained at the district level showed a decrease of cotton fields' area on 2714 ha in accordance to remote sensing and on 3094 ha to statistical data. Prevalence of remote sensing data in hectares could be explained, probably by the inclusion of adjacent territories between the fields and further research is needed, which will mainly concentrate on the improvement of boundaries evaluations. Correlation between ground truth data and satellite data was found as 0.99 (Fig. 5).

\section{Conclusion}

Cotton is considered as a one of the most important amongst the essential products in Uzbekistan, which plays a prevailing role in economy of the country. Reliable remote sensing data help to produce more detailed spatial data. Spectral correlation classification method of NDVI profiles

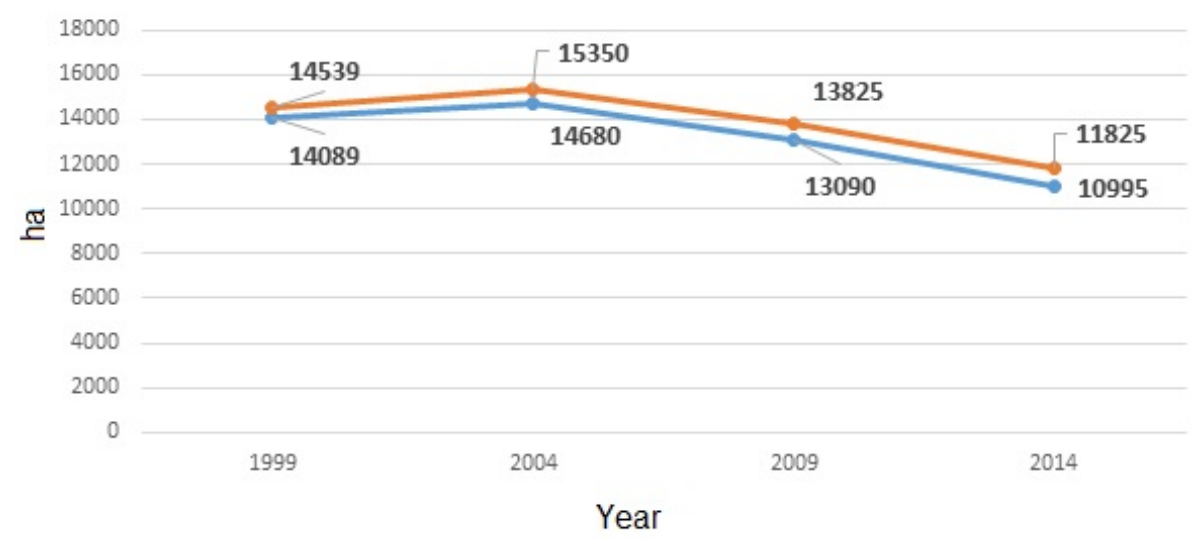

Fig. 5 Comparison of statistical (blue line) and classification (red line) data 
and combination of the results with Sentinel optical and radar data allowed to improve overall classification accuracy for 2017 from 89 to 93\% with a kappa coefficient varying from 0.89 to 0.95 . The results of the research demonstrated a noteworthy change in land use of Uzbekistan since the 1990s, in spite of the fact that there additionally has been a decreasing trend of cotton plantations after 2004. The appeared changes are connected to the changes in strategy of the country and progress to the grain autonomy.

The combination of different resolutions makes it possible to model the location of major crops based on NDVI values. In order to achieve a land use estimation with an accuracy higher than 85\%, at least seven scenes per year were necessary for the analysis. Improved confusion matrices of the classifications showed overall accuracies ranging between $89 \%$ and $93 \%$. Finally, an overlay of the classification results of 2017 in Google Earth (recorded in the same year) confirmed, that the results are reliable.

\section{Acknowledgement}

The research has been funded by TIIAME and ERASMUS CASIA project. The authors really grateful for the support to project coordinator Ewa Wietsma and would like to thank numerous colleagues at the Wageningen University and Research (the Netherlands) for all the stimulating discussions and assistance with data and analysis, especially associate professor Dirk Hoekman.

\section{References}

Cochran G (1977) Sampling techniques, 3rd edition, 1977, 448

Colditz RR, Schmidt M, Conrad C, Dech S (2011) Land cover classification with coarse spatial resolution data to derive continuous and discrete maps for complex regions. Remote Sensing of Environment 115, 3264-3275.

Congalton R (1991) A review of assessing the accuracy of classifications of remotely sensed data. Remote Sensing of Environment 37: 35-46.

Conrad C, Colditz R, Dech S, Klein D, Vlek P (2011) Improved irrigated crop classification in Central Asia using temporal segmentation and MODIS time series. International Journal of Remote Sensing 32 (23): 8763-8778.

Culbert PD, Pidgeon AM, St-Louis V, Bash D, Radeloff VC (2009) The impact of phonological variation on texture measures of remotely sensed imagery. IEEE J. Sel. Topics Appl. Earth Obs. Remote Sensing 2: 299-309.
De Carvalho OA, Júnior, Meneses PR (2000) Spectral Correlation Mapper (SCM): An Improvement on the Spectral Angle Mapper (SAM).

Dewit AJW, Clevers JGPW (2004) Efficiency and accuracy of perfield classification for operational crop mapping. International Journal of Remote Sensing 25(20): 4091-4112.

Djanibekov N, Rudenko I, Lamers J, Bobojonov I (2010) Pros and cons of cotton production in Uzbekistan, Case study 7-9 of the program: "Food policy for developing countries: the role of government in the global food system". Cornell University, Ithaca (NY).

Edlinger J, Conrad C, Lamers J, Khasankhanova G, Koellner T (2012) Reconstructing the spatio-temporal development of irrigation Systems in Uzbekistan using Landsat time Series. Remote Sensing 4: 3972-3994.

Furster S, Kaden K, Foerster M, Itzerott S (2012) Crop type mapping using spectral-temporal profiles and phenological information. Computers and Electronics in Agriculture 89: 30-40.

GEOSS (2009) Best practices for crop area estimation with Remote Sensing. In: Gallego J, Craig M, Michaelsen J, Bossyns B, Fritz S (eds) Joint Research Centre Scientific and Technical Reports (Ispra, June 5-6, 2008), European Communities, Luxembourg.

Glazirin GE, Chanishev SG, Chub VE (1999) Краткая характеристика климата Узбекистана (Brief outlines of climate in Uzbekistan).

Hamidov A, Helming K, Balla D (2016) Impact of agricultural land use in Central Asia: a review. Agronomy for Sustainable Development 36: 6 .

Heikkonen J, Varfis A (1998) Land cover/land use classificalton of urban areas: A remote sensing approach. International Journal of Pattern Recognition and Artificial Intelligence 12: 475-489.

Jensen JR (2005) Introductory digital image processing. A remote sensing perspective. Upper Saddle River, New Jersey.

Kahriz MP, Kahriz PP, Khawar KM (2019) Cotton Production in Central Asia. In: Jabran K, Singh Chauhan B (eds) Cotton Production. Wiley, New York, pp. 323-339.

Lillesand T, Kiefer R, Chipman J (2015) Remote sensing and image interpretation (7th edition). Wiley, New York.

Martinez-Casasnovas JA, Martin-Montero A, Casterad MA (2005) Mapping multi-year cropping patterns in small irrigation districts from time-series analysis of Landsat TM images. European Journal of Agronomy 23(2): 159-169.

Muttitanon W, Tripathi NK (2005) Land use/land cover changes in the coastal zone of Ban Don Bay, Thailand using Landsat 5 TM data. International Journal of Remote Sensing 26(11): 2311-2323.

Murthy CS, Raju PV, Badrinath KVS (2003) Classification of wheat crop with multi-temporal images: performance of maximum likelihood and artificial neural networks. International Journal of Remote Sensing 24: 4871-4890.

Odenweller JB, Johnson KI (1984) Crop identification using Landsat temporal spectral profiles. Remote Sensing of Environment 14: $39-54$

Platonov A, Thenkabail P, Biradar Ch (2008) Water Productivity Mapping (WPM) using Landsat ETM + data for the irrigated croplands of the Syrdarya River Basin in Central Asia. Sensors 8: 8156-8180.

Richards JA, Jia X (2006) Remote sensing digital image analysis - an introduction. Springer, Berlin-Heidelberg. 


\section{S sciendo}

Seto KC, Woodcock CE, Song C, Huang X, Lu J, Kaufmann RK (2002) Monitoring land use change in the Pearl River Delta using Landsat TM. International. Journal of Remote Sensing 23(10): 1985-2004.

Tian Y, Yin K, Lu D, Hua L, Zhao Q, Wen M (2014) Examining land use and land cover spatiotemporal change and driving forces in Beijing from 1978 to 2010. Remote Sensing 6: 10593-10611.

Turher M, Arikan M (2005) Sequential masking classification of multi-temporal Landsat7 ETM+ images for field-based crop mapping in Karacabey, Turkey. International Journal of Remote Sensing 26: 3813-3830.
USGS (UNITED STATES GEOLOGICAL SURVEY). Thematic Mapper; 2015. Available at: <http://eros.usgs.gov//Find Data/Products_and_Data_Available/TM>

Waske B, Braun M (2009) Classifier ensembles for land cover mapping using multi-temporal SAR imagery. ISPRS Journal of Photogrammetry and Remote Sensing 64(5): 450-457.

Yeshanev E, Wagner W, Exner-Kittridge M, Legesse D Blöschl G (2013) Identifying land use/cover dynamics in the Koga Catchment, Ethiopia, from multi-scale data, and implications for environmental change. ISPRS International Journal of GeoInformation 2: 302-323. 